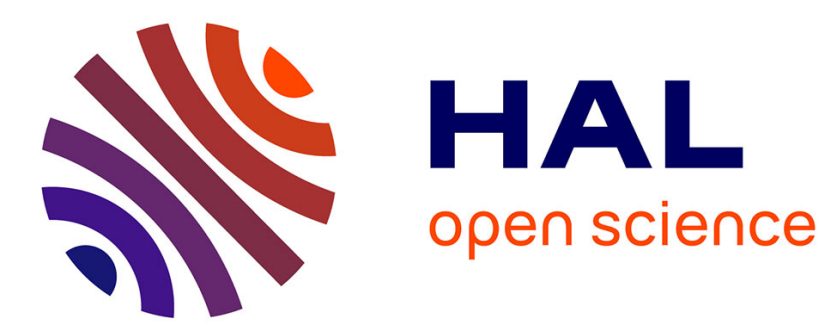

\title{
SAR analysis of wetland ecosystems: Effects of band frequency, polarization mode and acquisition dates
}

Sebastien Rapinel, Julie Betbeder, Julien Denize, Elodie Fabre, Eric Pottier, Laurence Hubert-Moy

\section{- To cite this version:}

Sebastien Rapinel, Julie Betbeder, Julien Denize, Elodie Fabre, Eric Pottier, et al.. SAR analysis of wetland ecosystems: Effects of band frequency, polarization mode and acquisition dates. ISPRS Journal of Photogrammetry and Remote Sensing, 2020, 170, pp.103-113. 10.1016/j.isprsjprs.2020.10.007 . hal-02998374v2

\section{HAL Id: hal-02998374 \\ https://hal.science/hal-02998374v2}

Submitted on 18 Jan 2021

HAL is a multi-disciplinary open access archive for the deposit and dissemination of scientific research documents, whether they are published or not. The documents may come from teaching and research institutions in France or abroad, or from public or private research centers.
L'archive ouverte pluridisciplinaire HAL, est destinée au dépôt et à la diffusion de documents scientifiques de niveau recherche, publiés ou non, émanant des établissements d'enseignement et de recherche français ou étrangers, des laboratoires publics ou privés. 


\title{
SAR analysis of wetland ecosystems: Effects of band frequency, polarization mode and acquisition dates
}

\author{
Sébastien Rapinel ${ }^{1}$, Julie Betbeder ${ }^{1}$, Julien Denize ${ }^{2}$, Élodie Fabre ${ }^{1}$, Éric Pottier ${ }^{2}$, and \\ Laurence Hubert-Moy ${ }^{1}$ \\ ${ }^{1}$ LETG UMR 6554 CNRS, University of Rennes, 35000 Rennes, France \\ ${ }^{2}$ Institute of Electronics and Telecommunications of Rennes IETR, UMR CNRS 6164, University of Rennes, 35000 \\ Rennes, France
}

Accepted version of the manuscript

\begin{abstract}
The availability of high spatial resolution synthetic aperture radar (SAR) sensors with a wide range of acquisition modes has increased greatly over the past decade and contributed significantly to the study of wetland ecosystems. However, the relative influence of acquisition configurations (i.e. band frequency, polarization mode, number of acquisition dates) in wetland analysis remains poorly explored. This article investigated the relative influence of X-/C-band frequency, dual-/quad-polarization and single-/multiacquisition features on discrimination of vegetation types in 632 ha Ramsar-protected temperate riverine marshes (Mont-Saint-Michel Bay, France). Three SAR datasets (i.e. quad-pol/C-band, dual-pol/C-band and dual-pol/X-band) were generated from five pairs of TerraSAR-X and RADARSAT-2 images. First, a set of 25 SAR features, including backscattering coefficients and polarimetric parameters, was extracted from the SAR datasets. Second, correlation between each pair of images was calculated using the polarimetric parameter Shannon entropy to select the most similar pairs in the time series. Third, the importance of each SAR feature and modeling accuracy were calculated using a conditional random forest model for each of the three datasets. Finally, analysis of variance was performed to assess the impact of band frequency, polarization mode and number of acquisition dates on the classification of vegetation types. The results highlighted that although the time-shift of each pair of TerraSAR-X and RADARSAT-2 images was short (3-11 days), only three pairs were sufficiently similar, highlighting the high variability in wetland ecosystems. The polarimetric parameter Shannon entropy was the most discriminating feature, regardless of the frequency or polarization. Most variance in the model accuracy was explained by the number of acquisition dates $(68 \%)$, followed by the frequency $(23 \%)$, while polarization explained little. This article will help select the most suitable SAR sensor acquisition modes for wetland conservation.
\end{abstract}

Keywords - ANOVA, Conservation, RADARSAT-2, TerraSAR-X, Random forest, Vegetation

\section{Introduction}

Wetland conservation is critically important to the planet, since wetlands provide hydrological, biogeochemical and ecological functions (Maltby and Barker 2009). However, most of these ecosystems are currently damaged or threatened, especially due to human modifications and agricultural intensification (Kingsford, Basset, and Jackson 2016). Managing and monitoring these highly dynamic and fine-grained patterned wetland ecosystems remain challenging due to limited field observations in time and space (S. Rapinel et al. 2019) and the limitations of optical remote sensing images due to cloud cover (Gallant 2015). In this context, many studies have recently highlighted the advantage of very high spatial resolution (1-10 m) SAR satellite data, such as ALOS-2, RADARSAT-2, TerraSAR-X or Sentinel-1 images, for monitoring and characterizing wetlands (Adeli et al. 2020; Mahdavi, Salehi, et al. 2018; Wohlfart et al. 2018). However, managers and scientists who use SAR data to study wetland ecosystems could be confused by the wide range of possible configurations of these data, such as polarization (dual- or quad-pol), frequency (C-, X- or L-band) and the number of acquisition dates, especially since the configuration influences the ability to discriminate different vegetation types (Mahdavi, Salehi, et al. 2018). In this context, Adeli et al (2020) recently highlighted the absence of consensus on the most appropriate SAR configuration to characterize wetlands and the need for future research. 

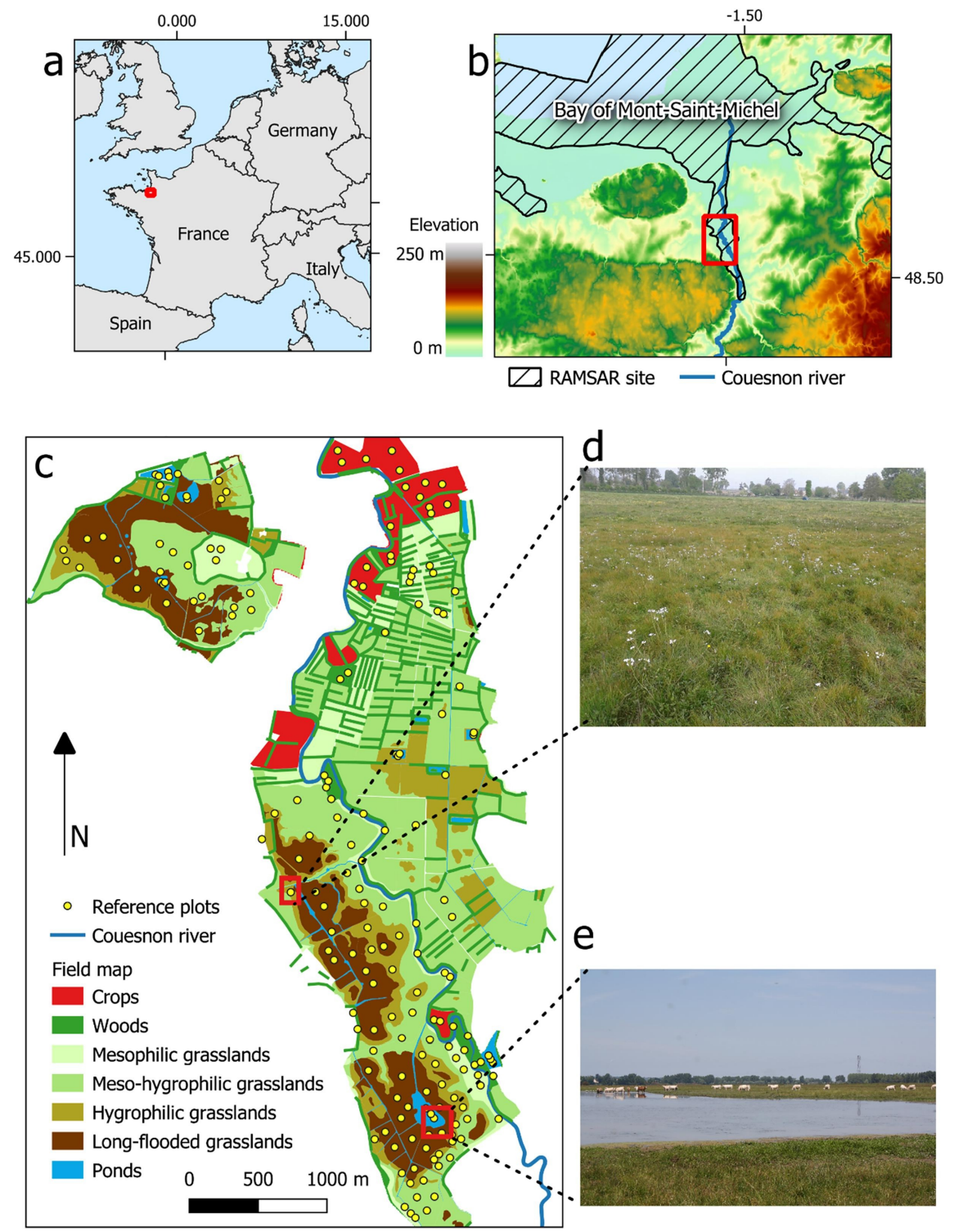

Figure 1: Study site presentation: (a) location in northwestern Europe, (b) location within the Couesnon valley included in the Ramsar-protected natural zone of Mont-Saint-Michel Bay, (c) location of reference plots and field map of vegetation in the marshes of the lower Couesnon valley (Lanoé, 2008), (d) field photograph of a hygrophilic grassland with Cardamine pratensis plant species (white flowers) and (e) field photograph of a pond surrounded by Eleocharis palustris plant species (long-flooded grassland).
SAR analysis of wetland ecosystems is particularly challenging given (i) the highly hydrodynamic nature of wetlands, with a flooded area that can change by several ha in a few days (Gallant 2015; Rapinel et al. 2018), and (ii) the strong impact of water on the SAR impulse response of wetland vegetation (Cazals et al. 2016; Mahdianpari, Salehi, Mohammadimanesh, and Brian Brisco 2017). Unfortunately, multi-sensor SAR data studies rarely considered the high spatiotemporal dynamics of wetland ecosystems. For example, RADARSAT-2 (quad-pol/C-band), Sentinel1 (dual-pol/C-band) and ALOS-2 (dual-pol/L-band) data acquired with time-shifts of 1-19 days were compared to discriminate peatland vegetation (Amani et al. 2019). Elsewhere, two time series, TerraSAR-X (dual-pol/X-band) and RADARSAT-2 (quad-pol/Cband), were acquired with 4-month time-shifts to map boreal wetlands (Mohammadimanesh, Salehi, Mahdianpari, Motagh, et al. 2018). In another study, one ALOS-1 (quad-pol/L-band) and one Sentinel-1 (dualpol/C-band) image with a 7-year time-shift were compared to delineate a wetland marsh (Simioni et al. 2019). Thus, new comparative analyses of band fre- quency, polarization mode and number of acquisition dates with SAR data acquired under similar hydrological and phenological conditions are needed.

The ability of SAR data to characterize wetlands also relies on the features used (Mahdavi, Salehi, et al. 2018). In this perspective, the relative influence of SAR features (i.e. polarimetric parameters and backscattering coefficients) on discrimination of wetland vegetation has been investigated extensively, although the conclusions differ depending on the features considered, the conditions under which SAR data were acquired and wetland type. For example, for quadpol C-band RADARSAT-2 data, some studies have demonstrated the advantage of polarimetric parameters from Cloude-Pottier decomposition over those from Freeman-Durden decomposition and backscattering coefficients to discriminate herbaceous (Morandeira et al. 2016) or boreal (B. Brisco et al. 2011) vegetation types. Conversely, other studies using also quadpol RADARSAT-2 data have highlighted the advantage of polarimetric parameters from Freeman-Durden decomposition over those from Cloude-Pottier decom- 
position to discriminate vegetation types in várzea forests (de Almeida Furtado, Silva, and de Moraes Novo 2016) or boreal wetlands (Mahdianpari, Salehi, Mohammadimanesh, Brian Brisco, et al. 2018; Mahdianpari, Salehi, Mohammadimanesh, and Brian Brisco 2017). In another study, the advantage of backscattering coefficients over polarimetric parameters from Freeman-Durden or Cloude-Pottier decomposition derived from L-band ALOS-2 and C-band RADARSAT2 was highlighted for the same boreal wetland site (Amani et al. 2019; Mohammadimanesh, Salehi, Mah- dianpari, Motagh, et al. 2018). In addition, while polarimetric parameters are frequently used in the quadpol configuration, they are rarely used in the dual-pol configuration, for example for X-band TerraSAR-X or C-band Sentinel-1 data (Amani et al. 2019; Betbeder, Sébastien Rapinel, Corgne, et al. 2015). Thus, the relative advantages of backscattering coefficients and polarimetric parameters for discriminating wetland vegetation types depending on the frequency and polarization of the SAR data remained an open issue and needed to be investigated more thoroughly.

Table 1: Description of vegetation types at the study site.

\begin{tabular}{|c|c|c|c|c|}
\hline Vegetation type & Typical plant species & Physiognomy & $\begin{array}{l}\text { Vegetation } \\
\text { height }(\mathrm{m})\end{array}$ & $\begin{array}{l}\text { Months } \\
\text { flooded per } \\
\text { year }\end{array}$ \\
\hline Crops & $\begin{array}{l}\text { Wheat } \\
\text { Maize }\end{array}$ & $\begin{array}{l}\text { Bare soil } \\
\text { Cereal }\end{array}$ & $0.0-2.0$ & $<1$ \\
\hline Woods & $\begin{array}{l}\text { Salix alba } \\
\text { Populus alba }\end{array}$ & Broadleaf tree & $6.0-20.0$ & $<1$ \\
\hline Mesophilic grasslands & $\begin{array}{l}\text { Festuca arundinacea } \\
\text { Arrhenatherum elatius }\end{array}$ & Herbaceous & $0.2-0.5$ & $<1$ \\
\hline Meso-hygrophilic grasslands & $\begin{array}{l}\text { Anthoxanthum odoratum } \\
\text { Bromus racemosus }\end{array}$ & Herbaceous & $0.1-0.3$ & $2-3$ \\
\hline Hygrophilic grasslands & $\begin{array}{l}\text { Oenanthe fistulosa } \\
\text { Cardamine pratensis }\end{array}$ & Herbaceous & $0.1-0.2$ & $3-6$ \\
\hline Long-flooded grasslands & $\begin{array}{l}\text { Glyceria fluitans } \\
\text { Eleocharis palustris }\end{array}$ & Herbaceous & $0.1-0.2$ & $6-8$ \\
\hline Ponds & $\begin{array}{l}\text { Myriophyllum spicatum } \\
\text { Lemna minor }\end{array}$ & \multicolumn{2}{|c|}{ Standing water $0.0-0.1$} & 12 \\
\hline
\end{tabular}

The influence of SAR data-acquisition configurations (i.e. band frequency, polarization mode, number of acquisition dates) on discrimination of wetland vegetation has been studied extensively in recent years (Mahdavi, Salehi Sr, et al. 2017; Wohlfart et al. 2018). Regarding band frequency, the advantage of the X-band over the C-band (Maleki et al. 2020; Mohammadimanesh, Salehi, Mahdianpari, Brian Brisco, and Motagh 2018) and S-band (van Beijma, Comber, and Lamb 2014) for discriminating wetland vegetation types has been described, as has the advantage of the Lband over the C-band for mapping emergent (Simioni et al. 2019) or woody (Amani et al. 2019; Mahdianpari, Salehi, Mohammadimanesh, and Motagh 2017) vegetations. The literature also describes the advantage of quad-polarized data over dual-polarized data to discriminate woody (de Almeida Furtado, Silva, and de Moraes Novo 2016; Mahdianpari, Salehi, Mohammadimanesh, and Motagh 2017) (de Almeida Furtado et al., 2016, Mahdianpari et al., 2017a) or boreal (Mahdianpari, Salehi, and Mohammadimanesh 2017) wet- land vegetation types. In addition, there is clear evidence that using multi-date data instead of singledate data for classifications increases the accuracy of wetland vegetation mapping significantly (Banks et al. 2019; Mahdianpari, Salehi, Mohammadimanesh, Brian Brisco, et al. 2018; Schuster et al. 2015), especially in spring images (Betbeder, Sébastien Rapinel, Corgne, et al. 2015; Jahncke et al. 2018). However, the relative influence of each acquisition configuration on discrimination of vegetation types in wetland ecosystems has never been addressed. This issue is crucial because the choice of which SAR data to acquire to study wetland ecosystems is a compromise among band frequency, polarization mode and number of acquisition dates.

This study investigated the relative influence of three SAR acquisition configurations (i.e. bandfrequency, polarization mode and number of acquisition dates) on discrimination of wetland vegetation types. To this end, we investigated three questions: 
(i) How similar are the acquisition parameters of SAR data collected by different sensors in wetland ecosystems?

(ii) Are the most discriminating SAR features of wetland vegetation the same regardless of the polarization or frequency used?

(iii) Is the influence of band frequency, polarization mode and number of acquisition dates the same regardless of vegetation type?

To answer these questions, 25 features were generated from RADARSAT-2 and TerraSAR-X images acquired over temperate riverine marshes. Random forest (RF) models were then used to discriminate seven wetland vegetation types, and analysis of variance (ANOVA) of classification accuracy scores was performed. The strengths and weaknesses of the method developed are discussed.

\section{Materials and methods}

\subsection{Study site and reference data}

The study focuses on 632 ha of wet grassland marshes in the Couesnon River floodplain, near Mont-SaintMichel Bay, France $\left(48.52^{\circ} \mathrm{N}, 1.53^{\circ} \mathrm{W}\right)$. The climate is temperate and humid (annual rainfall $1000 \mathrm{~mm}$ ) throughout the year. The site lies within the boundaries of environmentally protected areas (i.e. European Union Natura 2000 (1992/43/EEC) and international Ramsar). The topography is flat, with elevation 6-7 $\mathrm{m}$ above sea level. Grasslands are managed exclusively for mowing or alternate grazing/mowing cycles. A field vegetation map was created in 2008 at 1:2,500 scale from phytosociological surveys (Lanoé 2008). It highlights the dominance of four grassland vegetation types (Fig. 1) patterned by a gradient of flooding that ranges from 0 to 8 months/year (Marechal et al. 2012). The site contains smaller areas of three other vegetation types: ponds, woods and crops (Table 1 ).

Reference plots were extracted from a vector map of field vegetation. Additional field observations in 2013 (Fig. 1d-e) confirmed that the vegetation pattern in the study area had remained stable from 2008 to 2013. To avoid mixed pixels, each of the 182 reference plots was selected in GIS within $3 \times 3$ SAR-pixel windows contained strictly within a polygon of a given vegetation type.

\section{$2.2 \quad$ Satellite data}

The initial satellite dataset consisted of five pairs (i.e. "time-steps") of dual-pol RADARSAT-2 and dual-pol TerraSAR-X images acquired in 2013 from late winter to mid-summer (Table 2). To minimize bias due to environmental dynamics such as flooding and grassland mowing, we selected dates for each pair of acquisitions that were close in time. Based on the literature, we chose an incidence angle $>30^{\circ}$ to maximize vegetation penetration and water detection (Mahdavi, Salehi Sr, et al. 2017). All SAR satellite data were acquired in single look complex mode (i.e. Single Look Complex for RADARSAT-2 and Single Look Slant Range Complex for TerraSAR-X). Specifically, RADARSAT-2 images were acquired in Fine Quad polarization mode ( $\mathrm{HH}, \mathrm{HV}, \mathrm{VH}$ and VV polarization channels); with an incidence angles of $30-47^{\circ}$ and an approximate pixel size of $4 \times 8 \mathrm{~m}$. TerraSAR-X images were acquired in High-Resolution SpotLight mode $(\mathrm{HH}$ and VV polarization channels), with an incidence angle of $36-37^{\circ}$ and a pixel size of $1.8 \times 1.0 \mathrm{~m}$.

Table 2: Characteristics of the five pairs of SAR images acquired for the study from TerraSAR-X (TSX) and RADARSAT-2 (RST-2) sensors.

\begin{tabular}{|c|c|c|c|c|c|}
\hline $\begin{array}{l}\text { Time- } \\
\text { step }\end{array}$ & Sensor & Acquisition date & $\begin{array}{l}\text { Time- } \\
\text { shift }\end{array}$ & $\begin{array}{l}\text { Spatial } \\
\text { resolution } \\
\text { (azimuth } \\
\times \text { ground) }\end{array}$ & $\begin{array}{l}\text { Acquisition } \\
\text { angle }\end{array}$ \\
\hline \multirow{2}{*}{1} & TSX & Feb. 14, 2013 & \multirow{2}{*}{2 days } & $1.8 \times 1.0 \mathrm{~m}$ & $36-37^{\circ}$ \\
\hline & RST-2 & Feb. 16, 2013 & & $4.7 \times 6.4 \mathrm{~m}$ & $46-48^{\circ}$ \\
\hline \multirow{2}{*}{2} & TSX & March 10, 2013 & \multirow{2}{*}{3 days } & $1.8 \times 1.0 \mathrm{~m}$ & $36-37^{\circ}$ \\
\hline & RST-2 & March 13, 2013 & & $4.8 \times 8.1 \mathrm{~m}$ & $34-36^{\circ}$ \\
\hline \multirow{2}{*}{3} & TSX & April 15, 2013 & \multirow{2}{*}{2 days } & $1.8 \times 1.0 \mathrm{~m}$ & $36-37^{\circ}$ \\
\hline & RST-2 & April 13, 2013 & & $4.8 \times 7.4 \mathrm{~m}$ & $37-39^{\circ}$ \\
\hline \multirow{2}{*}{4} & TSX & May 4, 2013 & \multirow{2}{*}{11 days } & $1.8 \times 1.0 \mathrm{~m}$ & $36-37^{\circ}$ \\
\hline & RST-2 & April 23, 2013 & & $5.5 \times 9.0 \mathrm{~m}$ & $30-31^{\circ}$ \\
\hline \multirow{2}{*}{5} & TSX & July 20, 2013 & \multirow{2}{*}{11 days } & $1.8 \times 1.0 \mathrm{~m}$ & $36-37^{\circ}$ \\
\hline & RST-2 & July 31,2013 & & $4.9 \times 7.6 \mathrm{~m}$ & $37-39^{\circ}$ \\
\hline
\end{tabular}

\subsection{Generation of three SAR datasets}

From the full SAR images acquired, the objective was to generate three different datasets corresponding to three equivalent acquisition configurations (quadpol/C-band-Band, dual-pol/C-band-Band and dual$\mathrm{pol}$ (X-band-Band) to be able to compare the band frequencies and channel polarizations of RADARSAT-2 and TerraSAR-X.

After radiometrically calibrating all images, RADARSAT-2 images were converted from quad- to dual-polarization, and TerraSAR-X images were resampled at the spatial resolution of RADARSAT-2 images:

(i) The quad-pol/C-band dataset was produced directly from RADARSAT-2 images.

(ii) The dual-pol/C-band dataset was produced by extracting the $\mathrm{HH}$ and $\mathrm{VV}$ polarization channels, then deriving for each pixel of the RADARSAT-2 image the corresponding $2 \times 2$ covariance matrix $\mathrm{C}_{2}$.

(iii) The dual-pol/X-band dataset was produced by applying a multilook of three looks in azimuth and five in the range direction to the $2 \times 2$ covariance matrix $C_{2}$ of each pixel of the TerraSAR-X image. As a result, this dataset had a spatial resolution similar to that of the other two datasets. 
Table 3: Acronyms and description of the 25 SAR features used in this study per polarization mode.

\begin{tabular}{|c|c|c|c|}
\hline Acronym & SAR feature description & Quad-pol & Dual-pol \\
\hline $\mathrm{HH}$ & Horizontal transmit and horizontal receive & $\sqrt{ }$ & $\sqrt{ }$ \\
\hline VV & Vertical transmit and vertical receive & $\sqrt{ }$ & $\sqrt{ }$ \\
\hline $\mathrm{HV}$ & Horizontal transmit and vertical receive & $\sqrt{ }$ & \\
\hline $\mathrm{HH} / \mathrm{VV}$ & Co-polarization ratio & $\sqrt{ }$ & $\sqrt{ }$ \\
\hline $\mathrm{HH} / \mathrm{HV}$ & Co-polarization ratio & $\sqrt{ }$ & \\
\hline $\mathrm{VV} / \mathrm{HV}$ & Co-polarization ratio & $\sqrt{ }$ & \\
\hline $\mathrm{T}_{11}$ & First diagonal element from the coherency matrix & $\sqrt{ }$ & \\
\hline $\mathrm{T}_{22}$ & Second diagonal element from the coherency matrix & $\sqrt{ }$ & \\
\hline $\mathrm{T}_{33}$ & Third diagonal element from the coherency matrix & $\sqrt{ }$ & \\
\hline $\mathrm{C}_{11}$ & First diagonal element from the covariance matrix & & $\sqrt{ }$ \\
\hline $\mathrm{C}_{22}$ & Second diagonal element from the covariance matrix & & $\sqrt{ }$ \\
\hline $\mathrm{CP}_{-}$alpha & Alpha angle from Cloude-Pottier decomposition & $\sqrt{ }$ & \\
\hline $\mathrm{CP}_{-}$aniso & Anisotropy from Cloude-Pottier decomposition & $\sqrt{ }$ & \\
\hline $\mathrm{CP}_{-}$ent & Entropy from Cloude-Pottier decomposition & $\sqrt{ }$ & \\
\hline FD_vol & Volume scattering from Freeman-Durden decomposition & $\sqrt{ }$ & \\
\hline FD_dbl & Double-bounce scattering from Freeman-Durden decomposition & $\sqrt{ }$ & \\
\hline FD_odd & Single-bounce scattering from Freeman-Durden decomposition & $\sqrt{ }$ & \\
\hline Yam_vol & Volume scattering from Yamaguchi decomposition & $\sqrt{ }$ & \\
\hline Yam_dbl & Double-bounce scattering from Yamaguchi decomposition & $\sqrt{ }$ & \\
\hline Yam_odd & Single-bounce scattering from Yamaguchi decomposition & $\sqrt{ }$ & \\
\hline Yam_hlx & Helix scattering from Yamaguchi decomposition & $\sqrt{ }$ & \\
\hline SE & Sum of the Shannon entropy intensity and polarization & $\sqrt{ }$ & $\sqrt{ }$ \\
\hline $\mathrm{Se}_{\mathrm{i}}$ & Shannon entropy intensity & $\sqrt{ }$ & $\sqrt{ }$ \\
\hline $\mathrm{Se}_{\mathrm{p}}$ & Shannon entropy polarization & $\sqrt{ }$ & $\sqrt{ }$ \\
\hline SPAN & Total scattered power & $\sqrt{ }$ & $\sqrt{ }$ \\
\hline
\end{tabular}

\subsection{Extracting SAR features}

Next, the most frequently used SAR features (Adeli et al. 2020), including backscattering coefficients and polarimetric parameters (Table 3), were extracted from the three configuration datasets defined previously.

\subsubsection{Quad-pol dataset}

Backscattering coefficients $\left(\sigma^{\circ} \mathrm{HH}, \sigma^{\circ} \mathrm{VV}\right.$ and $\left.\sigma^{\circ} \mathrm{HV}\right)$ were extracted from the quad-pol/C-band dataset and then despeckled using the refined Lee filter (Lee and Eric Pottier 2009) with a sliding window of $7 \times 7$ pixels (sigma 0.8 , target $3 \times 3$ pixels). Next, the images were geocoded using Shuttle Radar Topography Mission (SRTM) data with a pixel spacing of $7 \mathrm{~m}$ (nearest neighbor resampling) to correct topographic deformations (geometric correction accuracy $<1$ pixel) and were then projected into the Lambert-RGF93/IGN-69 system. Three intensity ratios $(\mathrm{HH} / \mathrm{VV}, \mathrm{VV} / \mathrm{HV}$ and
$\mathrm{HH} / \mathrm{HV}$ ) were calculated from the images and converted into decibels $(\mathrm{dB})$ using the following equation:

$$
\sigma^{\circ}(d b)=10 \cdot \log _{10}(\sigma)^{\circ}
$$

Quad-polarimetric parameters were also generated from this dataset, as follows:

(i) A $3 \times 3$ coherency matrix $\left(T_{3}\right)$ and a $3 \times 3$ covariance matrix $\left(C_{3}\right)$ were extracted from each pixel of the SAR image described by its each scattering matrix $(S)$.

(ii) Speckle filtering was applied to the coherency $\left(T_{3}\right)$ and covariance $\left(C_{3}\right)$ matrices using a refined Lee filter with a sliding window of $7 \times 7$ pixels.

(iii) Geometric correction was applied to the coherency $\left(T_{3}\right)$ and covariance $\left(C_{3}\right)$ matrices using SRTM data with a pixel spacing of $7 \mathrm{~m}$ (nearest neighbor resampling).

(iv) First $T_{11}\left\langle\left|S_{H H}+S_{V V}\right|^{2}\right\rangle$, as well as second $T_{22}\left\langle\left|S_{H H}-S_{V V}\right|^{2}\right\rangle$ and third $T_{33}\left\langle\left|S_{H V}\right|^{2}\right\rangle$ el- 

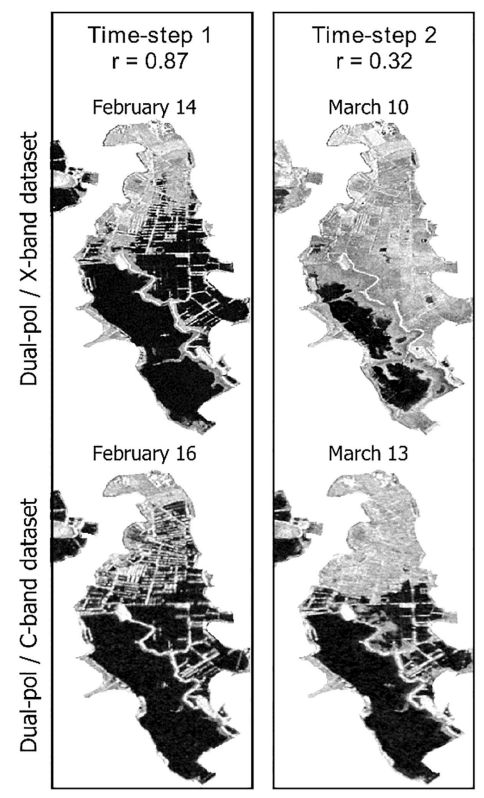

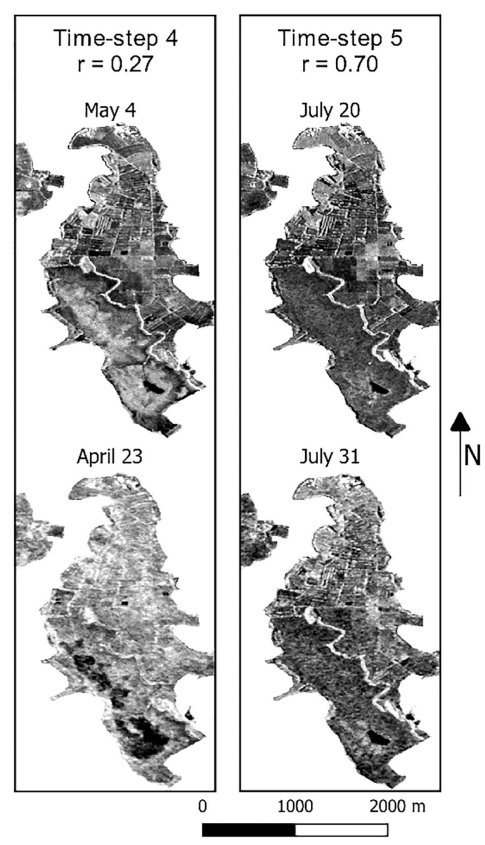

Figure 2: Comparison (using Pearson's correlation coefficient) of the similarity of five pairs of Shannon entropy images from the dual-pol/X-band and dual-pol/C-band datasets. Black areas (lower values) indicate flooded areas, while white areas (higher values) indicate woods or crops.). ements of the diagonal coherency matrix were used to describe single-bounce, double-bounce and volume-scattering mechanisms, respectively.

(v) Cloude-Pottier decomposition (Cloude and E. Pottier 1997) was performed on the coherency matrix $\left(T_{3}\right)$ to generate entropy ( $\mathrm{CP} \_$ent), alpha angle ( $\mathrm{CP}_{-}$alpha) and anisotropy $\left.\mathrm{CP}_{\text {_aniso }}\right)$ polarimetric parameters.

(vi) Freeman-Durden decomposition (Freeman and Durden 1998) was performed on the covariance matrix $\left(C_{3}\right)$ to generate single-bounce scattering (FD_odd), double-bounce scattering (FD_dbl) and volume scattering (FD_vol) parameters.

(vii) Yamaguchi decomposition (Yamaguchi et al. 2005) was performed on the covariance matrix $\left(C_{3}\right)$ to generate single-bounce scattering (Yam_odd), double-bounce scattering (Yam_dbl), volume scattering (Yam_vol) and helix scattering (Yam_hlx) parameters.

(viii) The shannon entropy parameters ( $\mathrm{SE}, \mathrm{SE}_{\mathrm{i}}$ and $\mathrm{SE}_{\mathrm{p}}$ ), as well as the total scattered power (SPAN) were also calculated (Lee and Eric Pottier 2009).

\subsubsection{Dual-pol datasets}

Backscattering coefficients $\left(\sigma^{\circ} \mathrm{HH}\right.$ and $\left.\sigma^{\circ} \mathrm{VV}\right)$ and the ratio $\mathrm{HH} / \mathrm{VV}$ were generated from the dual-pol/Cband and dual-pol/X-band datasets using the method described previously for the quad-pol dataset. Dualpolarimetric parameters were then extracted from the two datasets as follows:

\subsection{Ranking the importance of SAR features for discriminating wetland vegetation types}

The next step identified the SAR features and dates that discriminated wetland vegetation types the most (i) From each pixel of the SAR image described by its scattering elements, the corresponding $2 \times 2$ covariance matrix $\left(C_{2}\right)$ was extracted.

(ii) Speckle filtering was applied to the covariance matrix $\left(C_{2}\right)$ using a refined Lee filter with a sliding window of $7 \times 7$ pixels.

(iii) Geometric correction was applied to the covariance matrix $\left(C_{2}\right)$ using SRTM data with a pixel spacing of $7 \mathrm{~m}$ (nearest neighbor resampling).

(iv) First $C_{11}\left|S_{H H}\right|^{2}$ and second $C_{22}\left|S_{V V}\right|^{2}$ elements of the diagonal covariance matrix $\left(C_{2}\right)$ were extracted.

(v) SE, SE, $\mathrm{SE}_{\mathrm{p}}$ and $\mathrm{SPAN}$ were calculated (Lee and Eric Pottier 2009).

\subsection{Selection of similar pairs of images}

To ensure that the pairs of images were sufficiently similar to compare given the high temporal variability in wetland hydrodynamics, a Pearson correlation coefficient ( $\mathrm{r}$ ) was calculated between the SE of each pair of images in each dual-pol dataset. SE was selected because it is highly sensitive to the presence of open water, which varies greatly in wetland ecosystems (Marechal et al. 2012). Based on the conventional approach and visual analysis (Schober, Boer, and Schwarte 2018), image pairs with $r<0.7$ were considered as moderate or weak correlation and were excluded from subsequent analysis.

for each of the three SAR datasets. First, all pixel values of SAR features were standardized by setting the overall mean of each feature to 0 and the standard deviation to 0.25 , since the wide range of pixel values among SAR features and dates could have caused certain features to dominate the classification. Then, 


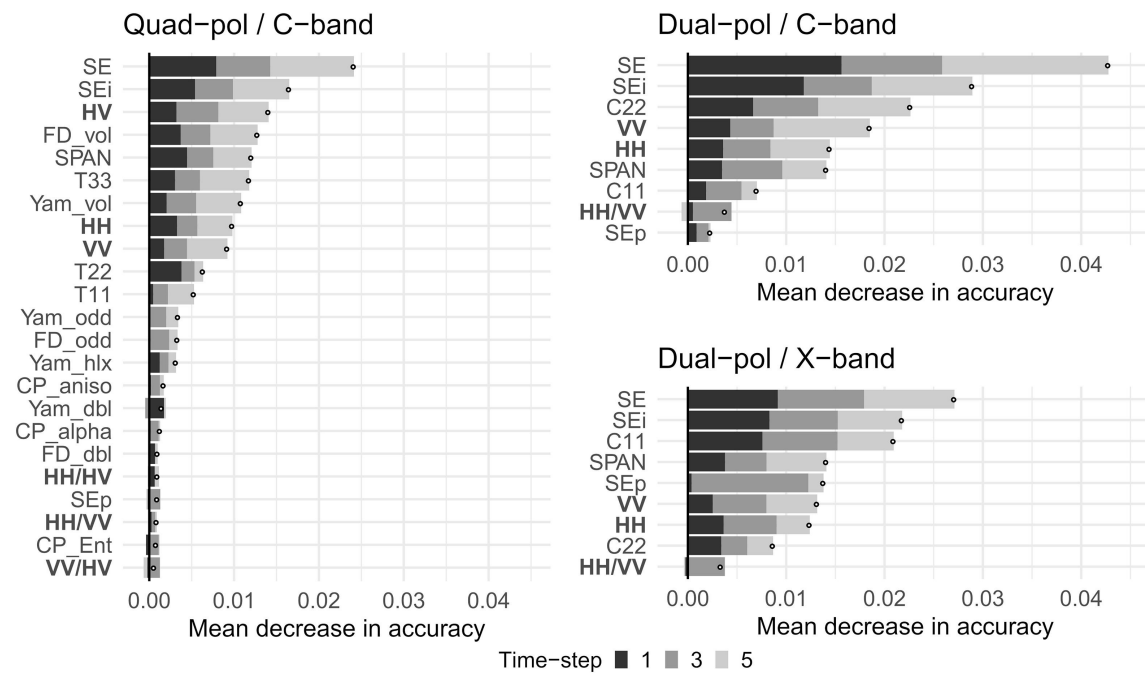

Figure 3: Mean decrease in accuracy cumulated per time-step of SAR features (see Table 3 for definitions) for wetland vegetation discrimination calculated using the random forest model for each of three SAR datasets. Backscattering coefficients are in bold font, while polarimetric parameters are in regular font. Dots indicate the cumulative mean decrease in accuracy. for each SAR dataset, the values of SAR features were extracted for each reference plot, and a specific conditional RF model (Strobl, Boulesteix, Kneib, et al. 2008), calibrated and validated by 5 -fold crossvalidation repeated two times (Kuhn and Johnson 2013), was fitted. Compared to the commonly used RF model (Breiman 2001), the conditional RF algorithm is designed to avoid ranking bias of correlated variables (Strobl, Boulesteix, Zeileis, et al. 2007), as may be the case with SAR features. To this end, the conditional RF model was first calibrated using conditional inference trees constructed on subsampling without replacement (Strobl, Boulesteix, Zeileis, et al. 2007), then SAR features were ranked by conditional permutation (Debeer and Strobl 2020). A cumulative mean decrease in accuracy was calculated for each SAR dataset for each feature and each date. Features or dates with a high mean decrease in accuracy influenced the RF modeling of wetland vegetation types the most.

\subsection{ANOVA of model output}

To quantify the percentage of the variance in model output (F1 scores) explained by polarization, frequency and the number of acquisition dates, ten F1 scores were derived per model (i.e. 5 folds $\times 2$ replicates) of the $\mathrm{RF}$ model for each SAR dataset. To quantify the influence of the number of acquisition dates on model accuracy, the conditional RF model was replicated for each of the three datasets with the 2 most important dates and then the most important date. As a result, for each dataset, the model was iteratively run with 3 dates, 2 dates and 1 date, respectively. An independent three-way ANOVA was performed for each vegetation type to estimate model accuracy based on its specific F1 scores as a function of polarization, frequency and number of acquisition dates. Similarly, another independent ANOVA was performed for all vegetation types based on global F1 scores. While some vegetation types violated the assumption of normality or heteroscedasticity, a three-way permutation ANOVA was performed (Wheeler, M. Torchiano, and M. M. Torchiano 2016) because this method is not restricted by distributional assumptions and accommodates differences among within-group distributions (Anderson 2014). Permutation ANOVA was performed using type III sum of squares since sample sizes differed (i.e. more dual-pol than quad-pol occurrences) (Shaw and Mitchell-Olds 1993). The percentage of variance in the F1 score explained by each factor (polarization, frequency and number of acquisition dates) in the ANOVA was calculated using the index $e t a^{2}$, which is the ratio of a factor's sum of squares to the total sum of squares (Cohen 2008).

\section{Results}

\subsection{Similar pairs of SAR images}

Comparison of the pairs of SE images from the dual$\mathrm{pol} / \mathrm{C}$-band and dual-pol/X-band datasets yielded $\mathrm{r}<$ 0.7 for time-steps 2 and 4, which were excluded from subsequent analysis (Fig. 2). In detail, time-step 1 (winter), with a time-shift of 2 days, revealed a large and similar area of marsh flooding on February 14 and $16(\mathrm{r}=0.87)$. Conversely, time-step 2 (winter), despite having a time-shift of only 3 days, revealed more marsh flooding on March 13 than on March 10, which yielded its low correlation $(\mathrm{r}=0.32)$. For time-step 3 (spring), the 2-day time-shift revealed a similar decrease in the flood area $(\mathrm{r}=0.83)$. For time-step 4 (spring), the longer time-shift (11 days) revealed much less open water area on May 4 than on April 23, which explained its low correlation $(\mathrm{r}=0.27)$. Conversely, time-step 5 (summer) also had a time-shift of 11 days, but its flooded area was similar $(r=0.70)$. Based on these results, three pairs of SAR images (time-steps 1, 3 and 5) were retained for subsequent analysis. 
Table 4: Results of a 3-factor permutation ANOVA that quantified the percentage of variance (expressed as $\left.e t a^{2}\right)$ in the accuracy of the random forest model (F1 score) of each vegetation type explained by polarization (POL), frequency (FREQ), number of acquisition dates (NOD) and their interactions.

\begin{tabular}{|c|c|c|c|c|c|}
\hline $\begin{array}{l}\text { Vegetation } \\
\text { type }\end{array}$ & POL & FREQ & NOD & $\begin{array}{l}\text { POL } \\
\times \\
\text { NOD }\end{array}$ & $\begin{array}{l}\text { FREQ } \\
\times \\
\text { NOD }\end{array}$ \\
\hline All types & $1.4^{* *}$ & $13.3^{* * *}$ & $68.4^{* * *}$ & $0.2 \mathrm{~ns}$ & $10.1^{* * *}$ \\
\hline Crops & $2.0^{*}$ & $10.1^{* * *}$ & $52.7^{* * *}$ & $3.5^{* *}$ & $0.7 \mathrm{~ns}$ \\
\hline Woods & $6.5^{* * *}$ & $1.4^{*}$ & $48.8^{* * *}$ & $8.5^{* * *}$ & $6.4^{* * *}$ \\
\hline $\begin{array}{l}\text { Mesophilic } \\
\text { grasslands }\end{array}$ & $2.9^{* * *}$ & $2.2^{* * *}$ & $58.0^{* * *}$ & $9.4^{* * *}$ & $19.4^{* * *}$ \\
\hline $\begin{array}{l}\text { Meso- } \\
\text { hygrophilic } \\
\text { grasslands }\end{array}$ & $4.8^{* * *}$ & $32.7^{* * *}$ & $27.1^{* * *}$ & $1.9^{*}$ & $8.0^{* * *}$ \\
\hline $\begin{array}{l}\text { Hygrophilic } \\
\text { grasslands }\end{array}$ & $0.7 \mathrm{~ns}$ & $0.1 \mathrm{~ns}$ & $64.8^{* * *}$ & $2.8^{* *}$ & $7.7^{* * *}$ \\
\hline $\begin{array}{l}\text { Long- } \\
\text { flooded } \\
\text { grasslands }\end{array}$ & $7.3^{* * *}$ & $17.3^{* * *}$ & $37.2^{* * *}$ & $5.6^{* * *}$ & $28.0^{* * *}$ \\
\hline Ponds & $2.2 \mathrm{~ns}$ & $1.4 \mathrm{~ns}$ & $0.8 \mathrm{~ns}$ & $1.0 \mathrm{~ns}$ & $6.2^{*}$ \\
\hline $\begin{array}{r}\text { Asterisks indi } \\
* * \mathrm{p}<0.0 \\
\text { non }\end{array}$ & $\begin{array}{l}\text { cate a si } \\
* \text { p }<\end{array}$ & $\begin{array}{l}\text { gnificant } \\
0.05) \text {, wh } \\
\text { ant result }\end{array}$ & $\begin{array}{l}\text { result ( } \\
\text { hile "ns" }\end{array}$ & $\begin{array}{l}(* * * \mathrm{p} \\
\text { " indice } \\
0.05) .\end{array}$ & $\begin{array}{l}0.001, \\
\text { tes a }\end{array}$ \\
\hline
\end{tabular}

For the quad-pol dataset, most discriminating of the $25 \mathrm{SAR}$ features were the polarimetric parameters SE $($ mean decrease in accuracy $=0.024)$ and $\mathrm{SE}_{\mathrm{i}}(0.016)$, followed by HV backscattering coefficient (0.014) (Fig. 3). Volume scattering, $\mathrm{HH}$ and VV backscattering coefficients, diagonal elements of the coherency matrix and SPAN were moderately discriminating (mean decrease in accuracy $=0.005-0.013$ ). The least discriminating features were the co-polarization and cross-polarization ratios; the parameters derived from Cloude-Pottier decomposition; and Yam_hlx, Yam_odd, Yam_dbl, FD_odd, FD_dbl and $\mathrm{SE}_{\mathrm{p}}$ (mean decrease in accuracy $<0.003$ ). Time-step 5 was the most important date (mean decrease in accuracy $=$ $0.061)$ while time-steps 3 and 1 were less contributing (0.047 and 0.043 , respectively).

For the dual-pol datasets, the most discriminating of the nine parameters were $\mathrm{SE}$ and $\mathrm{SE}_{\mathrm{i}}$ (mean decrease in accuracy $=0.042$ and 0.029 , respectively, in the C-band and 0.027 and 0.021 , respectively, in the X-band) (Fig. 3). Backscattering coefficients, diagonal elements of the covariance matrix and SPAN were moderately discriminating (mean decrease in accuracy
$=0.007-0.022$ in the C-band and 0.009-0.021 in the Xband). The co-polarization ratio was one of the least discriminating parameters in both C-band and X-band (mean decrease in accuracy $=0.004$ and 0.003 respectively). In the C-band, time-step 5 was the most important date (mean decrease in accuracy $=0.057$ ) while time-steps 3 and 1 were similarly less discriminating (0.048 and 0.047, respectively). Conversely, in the Xband, time-step 3 was the most important date (mean decrease in accuracy $=0.056)$, while time-steps 5 and 1 were similarly less discriminating (0.040 and 0.038 respectively).

\subsection{Influence of polarization, frequency and number of dates on discrimina- tion of wetland vegetation types}

Generally, results of the 3-factor permutation ANOVA indicated that both frequency and number of acquisition dates as well as their interactions influenced overall accuracy (F1 score) of the RF model significantly ( $\mathrm{p}$ $<0.001$ ) (Table 4). Conversely, polarization had little influence on overall accuracy $(\mathrm{p}<0.01)$, since the F1 scores had similar median values in dual-pol (0.59 \pm $0.09)$ and quad-pol $(0.60 \pm 0.11)$ modes (Table 4 and Fig. 4). Interactions between polarization and number of acquisition dates were non-significant $(p>0.05)$ when considering all wetland vegetation types. Conversely, for individual vegetation types, polarization influenced accuracy significantly $(\mathrm{p}<0.001)$, especially for discriminating woods, mesophilic grasslands, hygrophilic grasslands and long-flooded grasslands. More specifically, for woods, polarization and its interaction with the number of acquisition dates, explained $6.5 \%$ and $8.5 \%$ of the variance in model accuracy, respectively. Indeed, although the median F1 score was similar in quad-pol mode $(0.86 \pm 0.02)$ or dual-pol mode $(0.86 \pm 0.01)$ when two acquisition dates were used, it was much lower in dual-pol mode $(0.85 \pm 0.02)$ than in quad-pol mode $(0.92 \pm 0.02)$ when three acquisition dates were used (Fig. 5). For mesophilic grasslands, polarization and its interaction with the number of acquisition dates explained $2.9 \%$ and $9.4 \%$ of the variance in model accuracy, respectively, with higher F1 scores of 0.07 in dual-pol mode with three dates and even up to 0.16 with two dates (Fig. 5). For mesohygrophilic grasslands, polarization explained $4.8 \%$ of the variance in model accuracy, with higher F1 scores in dual-pol mode $(0.45 \pm 0.12)$ than in quad-pol mode $(0.37 \pm 0.10)$. For long-flooded grasslands, polarization also explained a part of the variance in model accuracy (7.3\%, p < 0.001), with higher F1 scores in quad-pol mode $(0.83 \pm 0.27)$ than in dual-pol mode $(0.71 \pm$ 0.20 ) (Fig. 4). The interaction between polarization and number of acquisition dates explained $5.6 \%$ of the variation in model accuracy for long-flooded grasslands $(\mathrm{p}<0.001)$, since the difference in F1 scores between quad-pol and dual-pol modes was larger $(0.85 \pm 0.02$ and $0.65 \pm 0.07$, respectively) when two acquisition dates were used (Fig. 5). A minor $(<4 \%)$ but signif- 
icant $(\mathrm{p}<0.05)$ influence of polarization and its interactions with the number of acquisition dates was observed for crops and hygrophilic grasslands (Table $4)$.

Frequency explained $13.3 \%(\mathrm{p}<0.001)$ of the variance in model accuracy for discriminating wetland vegetation types, since median F1 scores were slightly higher and with a lower variance in the X-band than the C-band (Fig. 4). The interaction between frequency and number of acquisition dates explained $10.1 \%(p<0.001)$ of the variance in overall model accuracy, since the advantage of the X-band over the C-band for the F1 score increased as the number of acquisition dates decreased (Fig. 5). Analysis of individual vegetation types indicated that frequency also influenced discrimination of each vegetation type significantly. For crops, frequency explained for $10.1 \%$ of the variance in overall model accuracy, with higher $\mathrm{F} 1$ scores in X-band frequency $(0.59 \pm 0.10)$ than in C-band frequency $(0.52 \pm 0.11)$ (Fig. 4). For woods, mesophilic grasslands and hygrophilic grasslands, interactions between frequency and the number of acquisition dates explained for $6.4 \%, 19.4 \%$ and $7.7 \%$ of the variance in overall model accuracy respectively. Whereas for woods, F1 scores were higher in C-band frequency than in X-band frequency except when two acquisition dates were used, conversely, for mesophilic and hygrophilic grasslands, F1 scores were higher in $\mathrm{X}$-band frequency than in C-band frequency except when 2 acquisition dates were used (Fig. 5). For meso-hygrophilic grasslands, frequency and its interactions with the number of acquisition dates explained for $32.7 \%$ and $8 \%(p<0.001)$ of the variance in model accuracy respectively, since F1 scores were globally higher in the $\mathrm{X}$-band $(0.49 \pm 0.06)$ than in the C-bands $(0.35 \pm 0.11)$ (Fig. 4). Though, F1 scores were similar in frequency $(0.53 \pm 0.03$ in X-band, and $0.52 \pm$ 0.04 in C-band) when three acquisition dates were used (Fig. 5). For long-flooded grasslands, frequency and its

\section{Discussion}

\subsection{How similar are the acquisition pa- rameters of SAR data collected by different sensors in wetland ecosys- tems?}

We acquired five pairs of RADARSAT-2 and TerraSAR-X images with time-shifts of $2-11$ days because it had been identified as acceptable (Amani et al. 2019; Mohammadimanesh, Salehi, Mahdianpari, Motagh, et al. 2018; Simioni et al. 2019). After the correlation analysis, however, we excluded two pairs (timesteps 2 and 4) that, despite having short time-shifts (3 and 11 days, respectively), showed large differences in flooded area and thus in the values of SAR features (Fig. 2). Without this verification step, all five timesteps would have been retained, and comparisons of the interactions with the number of acquisition dates explained for $17.3 \%$ and $28 \%(\mathrm{p}<0.001)$ of the variance in model accuracy respectively. Although F1 scores were similar regardless of the frequency when using two or three acquisition dates, scores differed greatly when using only one acquisition date, with clear discrimination in the X-band $(0.72 \pm 0.02)$ but poor discrimination in the C-band $(0.26 \pm 0.07)$. Interactions of frequency with the number of acquisition dates also influenced slightly $(6.2 \%)$ but less significantly $(\mathrm{p}<0.05)$ discrimination of ponds (Table 4 ).

The number of acquisition dates explained more than half of the variance in model accuracy $(68.4 \%, \mathrm{p}$ $<0.001$ ) (Table 4), with the median F1 score equal to $0.45 \pm 0.07$ with one date, $0.59 \pm 0.02$ with two dates and $0.69 \pm 0.03$ with three dates (Fig. 4). Moreover, the number of acquisition dates significantly explained $(p<0.001)$ for variance in model accuracy for each vegetation class except for ponds (Table 4). In details, analysis of individual vegetation types indicated that discrimination of crops $(46 \%, \mathrm{p}<0.001)$, woods $(48 \%$, $\mathrm{p}<0.001)$, and hygrophilic grasslands $(64.8 \%, \mathrm{p}<$ $0.001)$ depended greatly on the number of acquisition dates, with the F1 score increasing significantly from one to two acquisition dates for crops $(0.50 \pm 0.12$ and $0.68 \pm 0.07$, respectively), woods $(0.85 \pm 0.15$ and 0.91 \pm 0.03 , respectively) and hygrophilic grasslands (0.23 \pm 0.07 and $0.45 \pm 0.07$, respectively); however, addition of a third acquisition date did not increase the F1 score significantly (Fig. 4). For mesophilic grasslands, the number of acquisition dates explained $58 \%$ $(\mathrm{p}<0.001)$ of the variance in model accuracy, with the F1 score increasing as the number of acquisition dates increased $(0.26 \pm 0.11$ for 1 date, $0.35 \pm 0.13$ for 2 dates and $0.61 \pm 0.09$ for 3 dates) (Fig. 4). To a lesser extent, the number of acquisition dates also influenced discrimination of meso-hygrophilic grasslands, and long-flooded grasslands $(27.1-37.2 \%, \mathrm{p}<0.001)$ (Table 4).

frequency and polarization would have been biased by the large differences in hydrological conditions of the wetland ecosystems.

Our results confirm that wetland hydrodynamics vary throughout the year (Betbeder, Sébastien Rapinel, Corgne, et al. 2015): high variability occurred in late winter (time-series $2, \mathrm{r}=0.32$ ) and spring (timeseries $4, \mathrm{r}=0.27$ ), with time-shifts of 3 and 11 days, respectively, and relative stability (time-series $5, \mathrm{r}=$ 0.70) was observed in summer, with a time-shift of 11 days. Verifying image pairs is thus especially important during this dynamic late winter/spring period since it is the most discriminating for wetland vegetation (Jahncke et al. 2018). 


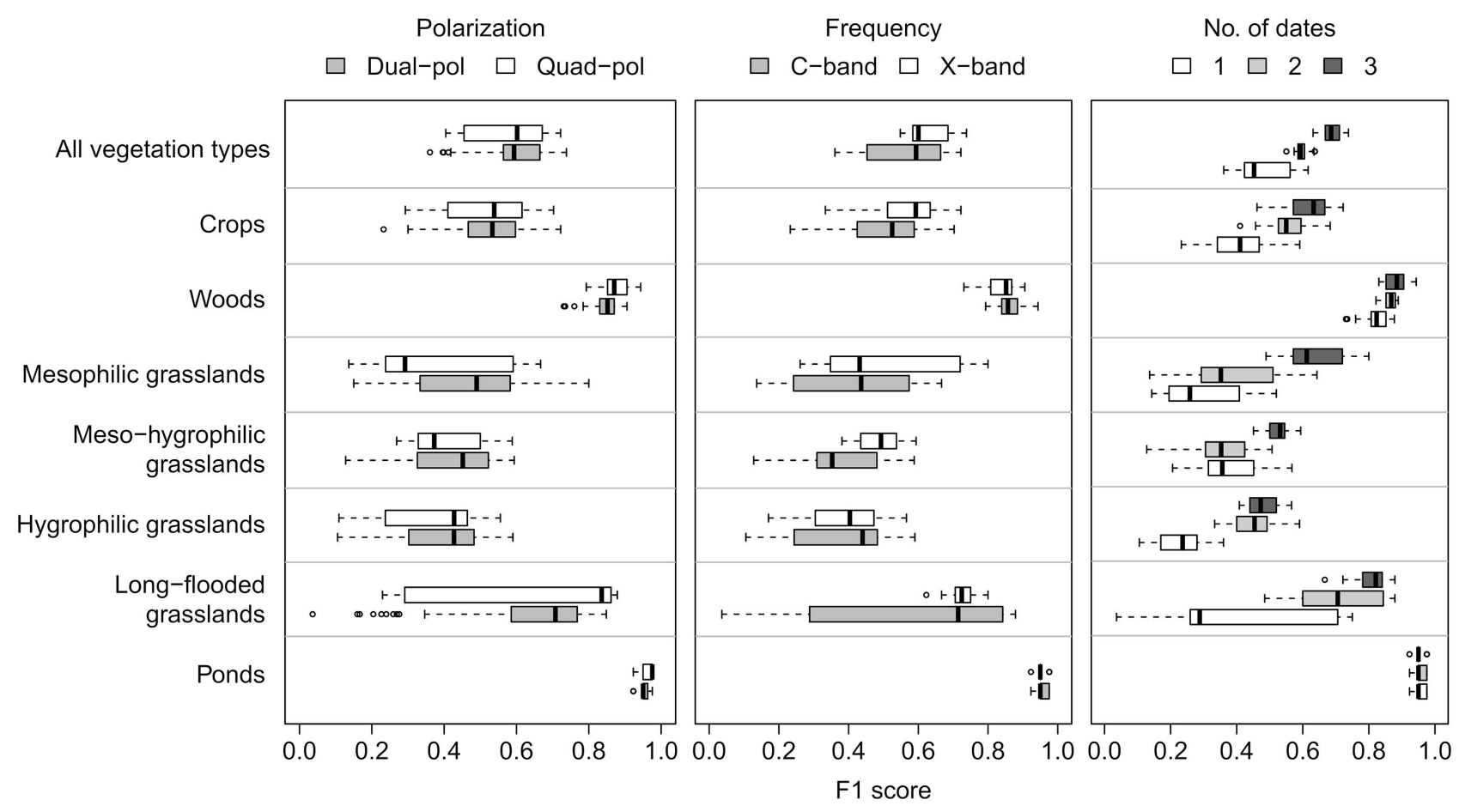

Figure 4: Variability in accuracy of the random forest model (F1 score) overall and for each wetland vegetation type as a function of polarization, frequency and number of acquisition dates of SAR datasets. Whiskers represent the 5 th and 95 th percentiles.

\subsection{Are the most discriminating SAR features of wetland vegetation the same regardless of the polarization or frequency used?}

This study highlights the advantage of SE features over backscattering coefficients or other polarimetric parameters for discriminating wetland vegetation, regardless of polarization (dual- or quad-pol) or frequency (C- or X-band). This result agrees with previous studies of this site performed using TerraSAR$\mathrm{X}$ images (Betbeder, Sébastien Rapinel, Corgne, et al. 2015; Betbeder, Sébastien Rapinel, Corpetti, et al. 2014). Conversely, Amani et al. (2019) found that SE was not highly discriminating for boreal wetlands using RADARSAT-2, ALOS-2 and Sentinel-1 images. This difference may be due to the type of wetland examined: in this study, the Couesnon marshes consisted basically of four types of wet meadows patterned by flood duration (Table 1), which SE clearly discriminated (Marechal et al. 2012). In quad-pol mode, SE was the most discriminating, even when including the parameters derived from polarimetric decompositions (Fig. 3). To a lesser extent, our results indicate the importance of Freeman-Durden and Yamagashi decomposition parameters, especially those related to volume scattering and, conversely, the low influence of parameters resulting from Cloude-Pottier decomposition, which agrees with some studies (de Almeida Furtado, Silva, and de Moraes Novo 2016; Mahdianpari, Salehi, Mohammadimanesh, Brian Brisco, et al. 2018; Mahdianpari, Salehi, Mohammadimanesh, and Motagh 2017) but contra- dicts others (Amani et al. 2019; Mohammadimanesh, Salehi, Mahdianpari, Motagh, et al. 2018; Morandeira et al. 2016).

In this study, we selected and tested 25 polarimetric $\mathrm{SAR}$ features among those commonly used in the literature for the study of wetlands (Adeli et al. 2020), although other polarimetric SAR features were occasionally investigated, such as those derived from Kennaugh (Mahdianpari, Salehi, Mohammadimanesh, and Brian Brisco 2017), Pauli (B. Brisco et al. 2011), Touzi (Amani et al. 2019; Franklin and Ahmed 2017; Millard and Richardson 2018) or Van Zyl (Amani et al. 2019; Mahdianpari, Salehi, Mohammadimanesh, Brian Brisco, et al. 2018) decompositions. While several studies recently highlighted the contribution of circular polarization features derived from compact polarization data (e.g. upcoming RADARSAT Constellation Mission) to discriminate wetland vegetation (Banks et al. 2019; Mohammadimanesh, Salehi, Mahdianpari, Brian Brisco, and Gill 2019), we did not test this specific feature as the Radarsat- 2 and TerraSAR-X data used were acquired in 2013 in dual or quad polarization.

Although we highlighted the advantage of SE, the importance of SAR features for discriminating wetland vegetation types differs among studies, since their importance depends greatly on the type of vegetation, reference data, type of model and the configuration used to acquire SAR data (Mohammadimanesh, Salehi, Mahdianpari, Brian Brisco, and Motagh 2018). 

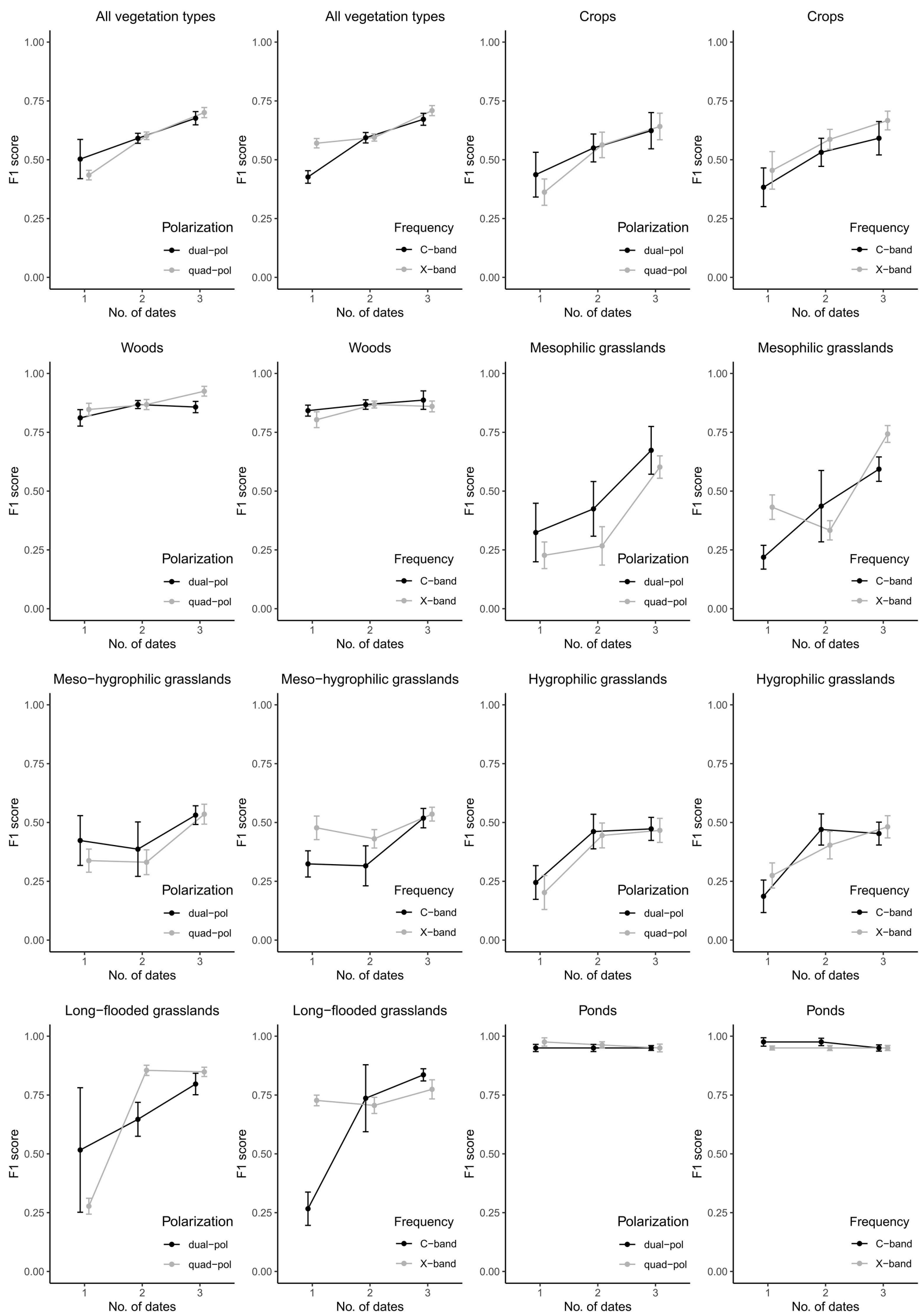

Figure 5: Influence of the three acquisition configurations (polarization, frequency, number of acquisition dates) and their interactions on the accuracy of the random forest model (median and standard deviation of the F1 score) overall and for each wetland vegetation type. Lines that are nearly parallel indicate weak interactions. 
Given this context, we recommend, as in the present study,comparing as many SAR features as possible and then retaining only the most discriminating ones to improve model performance and transferability (Maxwell, Warner, and Fang 2018). However, variable selection is a complex process, notably when many correlated variables such as SAR features are being considered (Gregorutti, Michel, and Saint-Pierre 2017). Despite the availability of a wide range of methods to select the most contributing variables - e.g. backward selection, dimension reduction space, specific internal metric, correlation analysis - there is no consensus on which one is the best. In this study, we addressed the question of the collinearity of the variables using a conditional permutation process (Debeer and Strobl 2020). However, further researches are still needed to develop a robust method for variable selection. In this perspective, Meyer et al. (2019) recently highlighted the importance of spatial predictor variable selection to improve machine learning model performance and transferability. This approach is attractive and deserves to be deeper investigated.

In this study, we used a variant of the random forest model, which is one of the most widely used models for mapping wetlands (Mahdavi, Salehi, et al. 2018). However, recent researches have highlighted the value of deep learning models to improve feature extraction (Sharifzadeh, Akbarizadeh, and Kavian 2019; Tirandaz, Akbarizadeh, and Kaabi 2020), change detection (Samadi, Akbarizadeh, and Kaabi 2019), or wetland mapping (DeLancey et al. 2020; Martins et al. 2020). Thus, the monitoring of wetland vegetations using deep learning modeling of SAR images appears to be a promising perspective.

\subsection{Is the influence of frequency, polar- ization and number of acquisition dates on model accuracy regardless of vegetation type?}

Our results indicate that polarization does not influence model accuracy, which does not agree with those of several studies that highlighted the advantage quadpol mode over dual-pol mode for discriminating wetland vegetation (Amani et al. 2019; de Almeida Furtado, Silva, and de Moraes Novo 2016; Mahdavi, Salehi Sr, et al. 2017). This difference can be explained by the high importance of SE for discriminating vegetation, which was calculated in both quad-pol and in dual-pol modes. Nonetheless, the advantage of quad-pol mode over dual-pol mode has been observed when identifying woods (with a height $>1 \mathrm{~m}$, Table 1 ), which are thus characterized well by volume-based polarimetric parameters (Freeman and Durden 1998; Yamaguchi et al. 2005), and identifying long-flooded grasslands with double-bounce scattering. Furthermore, our results show that the dual-pol configuration better discriminates herbaceous vegetations compared to the quad-pol configuration, although with a higher stan- dard deviation (Fig. 5). A possible explanation for this is that the dual-pol configuration includes two frequencies (X-band and C-band) exhibiting contrasting responses of herbaceous vegetations (Mahdianpari, Salehi, Mohammadimanesh, and Motagh 2017; Maleki et al. 2020; Mohammadimanesh, Salehi, Mahdianpari, Brian Brisco, and Motagh 2018), whereas the quad-pol configuration includes only one C-band frequency.

The most appropriate SAR frequency to characterize wetlands varies according to the physiognomy of the existing vegetation. In accordance with previous studies (Mahdianpari, Salehi, Mohammadimanesh, and Motagh 2017; Maleki et al. 2020; Mohammadimanesh, Salehi, Mahdianpari, Motagh, et al. 2018), our results indicate that model accuracy is higher in the X-band frequency than in the C-band frequency for herbaceous vegetations, especially when only one date is available. However, the findings show that C-band is slightly more relevant than $\mathrm{X}$-band to discriminate woody vegetations and ponds. In this study, L-band frequency SAR images, such as ALOS-2 data, were unfortunately unavailable during the period investigated, while several studies have highlighted the added value of the L-band over the C-band in discriminating woody vegetation such as swamps (Amani et al. 2019; Mahdianpari, Salehi, Mohammadimanesh, and Motagh 2017) or emergent vegetation such as marshes (Simioni et al. 2019). In summary, X-band frequency is the most discriminating for herbaceous vegetation, L-band or alternatively C-band for woody vegetation, and C-band for ponds. However, it should keep in mind that frequency and its interactions with the number of acquisition dates explain only for less than one-third of the variance in model accuracy (Table 4).

Indeed, our study confirms that classification accuracy increases as the number of acquisition dates increases (Banks et al. 2019; Mahdianpari, Salehi, Mohammadimanesh, Brian Brisco, et al. 2018; Schuster et al. 2015). The number of acquisition dates needed to achieve acceptable accuracy (F1 score > 0.8 ) ranges from one for woods and ponds, to two for long-flooded grasslands, to more than three for certain grassland vegetation types or crops (data not shown). Indeed, accurately discriminating the four grassland types requires characterizing flood duration using at least five acquisition dates (Betbeder, Sébastien Rapinel, Corgne, et al. 2015). More generally, our results emphasize that the number of acquisition dates explains more than half of the variance in the discrimination accuracy of wetland vegetation. Our results also validate the hypothesis of Schuster et al. (2015) that temporal resolution is more important than sensor characteristics. Nevertheless, a slight decrease in the F1 score was observed when the third acquisition was added for woods in X-band and ponds in C-band frequency (Fig. 5). This may be explained by the fact that the third acquisition date is the least important variable and therefore the one that introduces noise and complexity to the conditional RF model, 
decreasing the accuracy for some vegetation classes (Maxwell, Warner, and Fang 2018). In addition, a decrease in model accuracy was also reported in Xband between 1 and 2 acquisition dates for mesophilic, meso-hygrophilic and long-flooded grasslands. In fact, whereas time-step 5, which was acquired during the dry season, was the second most important variable for all the vegetation classes in X-band frequency, it did not discriminate between grassland classes, since these classes share the same phenological and hydrological characteristics at this period of the year. The relationships between vegetation condition, SAR signal response and modelling processes are complex and require future interdisciplinary research between ecology, remote sensing and modelling sciences.

\section{Conclusion}

Five pairs of RADARSAT-2 and TerraSAR-X images and ANOVA were used to investigate the relative influence of polarization, frequency and number of acquisition dates on the accuracy of a conditional RF model used to discriminate seven vegetation types in riverine marshes. Our results suggest that (i) the strong hydrological dynamics of wetlands require verifying the similarity of SAR image pairs before comparing acquisition configurations, (ii) SE is the most discriminating SAR feature regardless of polarization mode (dual-/quadpol) or frequency (X-/C-band) and (iii) the number of acquisition dates explains more than half of the variance in model accuracy. In other words, this study indicates that wetland vegetation types could be discriminated sufficiently well using SAR images and SE generated over a dense SAR time-series, regardless of the frequency or polarization.

\section{Acknowledgements}

This research was funded by the French Ministry of Higher Education, Research and Innovation as well as the French National Space Agency (CNES). The authors gratefully thank Elven Lanoé and Cendrine Mony (UMR ECOBIO) for providing the GIS vegetation map, as well as the Zone Atelier Armorique (CNRS) program for funding the additional fieldwork. RADARSAT-2 and TerraSAR-X data were acquired from the Canadian and German space agencies (DLR), respectively, and funded by the VIGISAT project of the Bretagne Télédétection (GIS BRETEL) consortium.

\section{References}

Adeli, Sarina et al. (2020). "Wetland Monitoring Using SAR Data: A Meta-Analysis and Comprehensive Review". In: Remote Sensing 12.14, p. 2190.

Amani, Meisam et al. (2019). "Separability Analysis of Wetlands in Canada Using Multi-Source
SAR Data". In: GIScience $\&$ Remote Sensing 56.8, pp. 1233-1260.

Anderson, Marti J. (2014). "Permutational Multivariate Analysis of Variance (PERMANOVA)". In: $W i$ ley StatsRef: Statistics Reference Online, pp. 1-15.

Banks, Sarah et al. (2019). "Wetland Classification with Multi-Angle/Temporal SAR Using Random Forests". In: Remote Sensing 11.6, p. 670.

Betbeder, Julie, Sébastien Rapinel, Samuel Corgne, et al. (Sept. 2015). "TerraSAR-X Dual-Pol TimeSeries for Mapping of Wetland Vegetation". In: ISPRS Journal of Photogrammetry and Remote Sensing. Multitemporal Remote Sensing Data Analysis 107, pp. 90-98. ISSN: 0924-2716. DOI: $10.1016 /$ j . isprsjprs . 2015 .05 .001. URL: http : //www . sciencedirect . com / science / article / pii / S0924271615001380 (visited on 01/15/2016).

Betbeder, Julie, Sébastien Rapinel, Thomas Corpetti, et al. (2014). "Multitemporal Classification of TerraSAR-X Data for Wetland Vegetation Mapping". In: Journal of Applied Remote Sensing 8.1, pp. 083648-083648. ISSN: 1931-3195. DOI: $10.1117 /$ 1. JRS . 8.083648. URL: http://dx .doi .org/10 . 1117/1. JRS.8.083648 (visited on 04/18/2014).

Breiman, Leo (Oct. 1, 2001). "Random Forests". In: Machine Learning 45.1, pp. 5-32. ISSN: 0885-6125, 1573-0565. DOI: $10.1023 / \mathrm{A}: 1010933404324$. URL: http : //link . springer . com/article/10 .1023/ A\%3A1010933404324 (visited on 06/12/2015).

Brisco, B. et al. (2011). "Evaluation of C-Band Polarization Diversity and Polarimetry for Wetland Mapping". In: Canadian Journal of Remote Sensing 37.1, pp. 82-92.

Cazals, Cécile et al. (July 5, 2016). "Mapping and Characterization of Hydrological Dynamics in a Coastal Marsh Using High Temporal Resolution Sentinel-1A Images". In: Remote Sensing 8.7, p. 570. DOI: $10.3390 /$ rs8070570. URL: http : / / wWw . mdpi . com/2072-4292/8/7/570 (visited on $07 / 05 / 2016)$.

Cloude, S. R. and E. Pottier (Jan. 1997). "An Entropy Based Classification Scheme for Land Applications of Polarimetric SAR". In: IEEE Transactions on Geoscience and Remote Sensing 35.1, pp. 68-78. ISSN: 0196-2892. DOI: 10.1109/36.551935.

Cohen, Jacob (2008). Statistical Power Analysis for the Behavioral Sciences (2nd Ed.) Hillsdale, NJ: Erlbaum. 566 pp. ISBN: 1-4832-7648-1.

De Almeida Furtado, Luiz Felipe, Thiago Sanna Freire Silva, and Evlyn Márcia Leão de Moraes Novo (2016). "Dual-Season and Full-Polarimetric C Band SAR Assessment for Vegetation Mapping in the Amazon Várzea Wetlands". In: Remote sensing of environment 174, pp. 212-222.

Debeer, Dries and Carolin Strobl (2020). "Conditional Permutation Importance Revisited". In: BMC bioinformatics 21.1, pp. 1-30.

DeLancey, Evan R. et al. (Jan. 2020). "Comparing Deep Learning and Shallow Learning for LargeScale Wetland Classification in Alberta, Canada". In: Remote Sensing 12.1 (1), p. 2. DOI: $10.3390 /$ 
rs12010002. URL: https : //www . mdpi . com/20724292/12/1/2 (visited on 08/24/2020).

Franklin, Steven E. and Oumer S. Ahmed (2017). "Object-Based Wetland Characterization Using Radarsat-2 Quad-Polarimetric SAR Data, Landsat8 OLI Imagery, and Airborne Lidar-Derived Geomorphometric Variables". In: Photogrammetric Engineering \& Remote Sensing 83.1, pp. 27-36.

Freeman, A. and S. L. Durden (May 1998). "A ThreeComponent Scattering Model for Polarimetric SAR Data". In: IEEE Transactions on Geoscience and Remote Sensing 36.3, pp. 963-973. ISSN: 0196-2892. DOI: $10.1109 / 36.673687$.

Gallant, Alisa L. (Aug. 24, 2015). "The Challenges of Remote Monitoring of Wetlands". In: Remote Sensing 7.8, pp. 10938-10950. DOI: 10 . 3390 / rs70810938. URL: http : / www . mdpi . com/2072 4292/7/8/10938 (visited on 10/04/2016).

Gregorutti, Baptiste, Bertrand Michel, and Philippe Saint-Pierre (2017). "Correlation and Variable Importance in Random Forests". In: Statistics and Computing 27.3, pp. 659-678.

Jahncke, Raymond et al. (June 1, 2018). "Mapping Wetlands in Nova Scotia with Multi-Beam RADARSAT-2 Polarimetric SAR, Optical Satellite Imagery, and Lidar Data". In: International Journal of Applied Earth Observation and Geoinformation 68, pp. 139-156. ISSN: 0303-2434. DOI: 10.1016/j . jag . 2018 . 01 .012. URL: http : / / www.sciencedirect.com/science/article/pii/ S0303243418300801 (visited on 11/12/2019).

Kingsford, Richard T., Alberto Basset, and Leland Jackson (2016). "Wetlands: Conservation's Poor Cousins". In: Aquatic Conservation: Marine and Freshwater Ecosystems 26.5, pp. 892-916. ISSN: 1099-0755. DOI: 10 . 1002 / aqc . 2709. URL: http : //onlinelibrary.wiley.com/doi/abs/10.1002/ aqc. 2709 (visited on 01/24/2020).

Kuhn, Max and Kjell Johnson (2013). Applied Predictive Modeling. New York, NY, USA: SpringerVerlag. 600 pp. ISBN: 978-1-4614-6848-6.

Lanoé, Elven (2008). Diagnostics Phyto-Écologique et Paysager Des Marais de La Basse Vallée Du Couesnon et de Leur Rôle Fonctionnel Potentiel En Terme d'accueil de l'avifaune. Rennes: Universite de Rennes 1, p. 42.

Lee, Jong-Sen and Eric Pottier (Feb. 2, 2009). Polarimetric Radar Imaging: From Basics to Applications. CRC Press. 432 pp. ISBN: 978-1-4200-5498-9.

Mahdavi, Sahel, Bahram Salehi Sr, et al. (2017). "A Comparison between Different Synthetic Aperture Radar (SAR) Sensors for Wetland Classification". In: Imaging and Geospatial Technology Forum, IGTF, pp. 12-16.

Mahdavi, Sahel, Bahram Salehi, et al. (2018). "Remote Sensing for Wetland Classification: A Comprehensive Review". In: GIScience \& Remote Sensing 55.5, pp. 623-658.

Mahdianpari, Masoud, Bahram Salehi, and Fariba Mohammadimanesh (2017). "The Effect of PolSAR Image De-Speckling on Wetland Classification: In- troducing a New Adaptive Method". In: Canadian Journal of Remote Sensing 43.5, pp. 485-503.

Mahdianpari, Masoud, Bahram Salehi, Fariba Mohammadimanesh, and Brian Brisco (2017). "An Assessment of Simulated Compact Polarimetric SAR Data for Wetland Classification Using Random Forest Algorithm". In: Canadian Journal of Remote Sensing 43.5, pp. 468-484.

Mahdianpari, Masoud, Bahram Salehi, Fariba Mohammadimanesh, Brian Brisco, et al. (2018). "Fisher Linear Discriminant Analysis of Coherency Matrix for Wetland Classification Using PolSAR Imagery". In: Remote Sensing of Environment 206, pp. 300317.

Mahdianpari, Masoud, Bahram Salehi, Fariba Mohammadimanesh, and Mahdi Motagh (2017). "Random Forest Wetland Classification Using ALOS-2 L-Band, RADARSAT-2 C-Band, and TerraSAR-X Imagery". In: ISPRS Journal of Photogrammetry and Remote Sensing 130, pp. 13-31.

Maleki, Saeideh et al. (2020). "Analysis of MultiFrequency and Multi-Polarization SAR Data for Wetland Mapping in Hamoun-e-Hirmand Wetland". In: International Journal of Remote Sensing 41.6, pp. 2277-2302.

Maltby, E. and T. Barker (2009). The Wetlands Handbook. Wiley-Blackwell. Oxford. 1058 pp.

Marechal, C. et al. (2012). "One Year Wetland Survey Investigations from a Quad-Pol Radarsat-2 Time Series SAR Images". In: Canadian Journal of Remote Sensing.

Martins, Vitor S. et al. (2020). "Deep Neural Network for Complex Open-Water Wetland Mapping Using High-Resolution WorldView-3 and Airborne LiDAR Data". In: International Journal of Applied Earth Observation and Geoinformation 93, p. 102215.

Maxwell, Aaron E., Timothy A. Warner, and Fang Fang (May 3, 2018). "Implementation of MachineLearning Classification in Remote Sensing: An Applied Review". In: International Journal of Remote Sensing 39.9, pp. 2784-2817. ISSN: 0143-1161. DOI: 10.1080/01431161 . 2018 . 1433343. URL: https : //www . tandfonline.com/doi/citedby/10.1080/ 01431161.2018 .1433343 (visited on 08/24/2018).

Meyer, Hanna et al. (2019). "Importance of Spatial Predictor Variable Selection in Machine Learning Applications-Moving from Data Reproduction to Spatial Prediction". In: Ecological Modelling 411, p. 108815.

Millard, Koreen and Murray Richardson (Mar. 1, 2018). "Quantifying the Relative Contributions of Vegetation and Soil Moisture Conditions to Polarimetric C-Band SAR Response in a Temperate Peatland". In: Remote Sensing of Environment 206, pp. 123-138. ISSN: 0034-4257. DOI: 10.1016/ j . rse . 2017 . 12 . 011. URL: https : / / www . sciencedirect . com / science / article / pii / S0034425717305862 (visited on 01/03/2018).

Mohammadimanesh, Fariba, Bahram Salehi, Masoud Mahdianpari, Brian Brisco, and Eric Gill (Jan. 
2019). "Full and Simulated Compact Polarimetry SAR Responses to Canadian Wetlands: Separability Analysis and Classification". In: Remote Sensing 11.5 (5), p. 516. DOI: $10.3390 /$ rs11050516. URL: https : / / www . mdpi . com/ 2072-4292/11/5/516 (visited on 09/10/2020).

Mohammadimanesh, Fariba, Bahram Salehi, Masoud Mahdianpari, Brian Brisco, and Mahdi Motagh (2018). "Multi-Temporal, Multi-Frequency, and Multi-Polarization Coherence and SAR Backscatter Analysis of Wetlands". In: ISPRS Journal of Photogrammetry and Remote Sensing 142, pp. 78-93.

Mohammadimanesh, Fariba, Bahram Salehi, Masoud Mahdianpari, Mahdi Motagh, et al. (2018). "An Efficient Feature Optimization for Wetland Mapping by Synergistic Use of SAR Intensity, Interferometry, and Polarimetry Data". In: International journal of applied earth observation and geoinformation 73, pp. $450-462$.

Morandeira, Natalia S. et al. (2016). "Mapping Plant Functional Types in Floodplain Wetlands: An Analysis of C-Band Polarimetric SAR Data from RADARSAT-2". In: Remote Sensing 8.3, p. 174.

Rapinel, S. et al. (Oct. 1, 2019). "Mapping Potential, Existing and Efficient Wetlands Using Free Remote Sensing Data". In: Journal of Environmental Management 247, pp. 829-839. ISSN: 0301-4797. DOI: 10 . 1016/ j . jenvman . 2019 . 06 . 098. URL: http : //www . sciencedirect . com/science / article / pii/S0301479719308990 (visited on 07/20/2019).

Rapinel, S et al. (Mar. 6, 2018). "Daily Monitoring of Shallow and Fine-Grained Water Patterns in Wet Grasslands Combining Aerial LiDAR Data and In Situ Piezometric Measurements". In: Sustainability 10.3, p. 708. DOI: $10.3390 /$ su10030708. URL: http : / / www . mdpi . com / 2071-1050 / 10 / 3 / 708 (visited on $03 / 06 / 2018$ ).

Samadi, Farnaam, Gholamreza Akbarizadeh, and Hooman Kaabi (2019). "Change Detection in SAR Images Using Deep Belief Network: A New Training Approach Based on Morphological Images". In: IET Image Processing 13.12, pp. 2255-2264.

Schober, Patrick, Christa Boer, and Lothar A. Schwarte (2018). "Correlation Coefficients: Appropriate Use and Interpretation". In: Anesthesia \& Analgesia 126.5, pp. 1763-1768.

Schuster, Christian et al. (Feb. 2015). "Grassland Habitat Mapping by Intra-Annual Time Series Analysis - Comparison of RapidEye and TerraSAR-X Satellite Data". In: International Journal of Applied Earth Observation and Geoinformation 34, pp. 25-
34. ISSN: 0303-2434. DOI: $10.1016 / \mathrm{j} \cdot \mathrm{jag} \cdot 2014$. 06.004. URL: http : //www. sciencedirect. com/ science/article/pii/S0303243414001378 (visited on $06 / 12 / 2015)$.

Sharifzadeh, Foroogh, Gholamreza Akbarizadeh, and Yousef Seifi Kavian (2019). "Ship Classification in SAR Images Using a New Hybrid CNN-MLP Classifier". In: Journal of the Indian Society of Remote Sensing 47.4, pp. 551-562.

Shaw, Ruth G. and Thomas Mitchell-Olds (1993). "ANOVA for Unbalanced Data: An Overview". In: Ecology 74.6, pp. 1638-1645.

Simioni, João Paulo Delapasse et al. (2019). "Integration of Multi-Sensor Analysis and Decision Tree for Evaluation of Dual and Quad-Pol SAR in L-and C-Bands Applied for Marsh Delineation". In: Environment, Development and Sustainability, pp. 118.

Strobl, Carolin, Anne-Laure Boulesteix, Thomas Kneib, et al. (2008). "Conditional Variable Importance for Random Forests". In: BMC bioinformatics 9.1, p. 307.

Strobl, Carolin, Anne-Laure Boulesteix, Achim Zeileis, et al. (Jan. 25, 2007). "Bias in Random Forest Variable Importance Measures: Illustrations, Sources and a Solution". In: BMC Bioinformatics 8.1, p. 25. ISSN: 1471-2105. DOI: $10.1186 / 1471-2105-8-25$. URL: https : //doi .org/10 . 1186/1471-2105-825 (visited on $06 / 10 / 2020$ ).

Tirandaz, Zeinab, Gholamreza Akbarizadeh, and Hooman Kaabi (2020). "PolSAR Image Segmentation Based on Feature Extraction and Data Compression Using Weighted Neighborhood Filter Bank and Hidden Markov Random Field-Expectation Maximization". In: Measurement 153, p. 107432.

Van Beijma, Sybrand, Alexis Comber, and Alistair Lamb (2014). "Random Forest Classification of Salt Marsh Vegetation Habitats Using QuadPolarimetric Airborne SAR, Elevation and Optical RS Data". In: Remote Sensing of Environment 149, pp. $118-129$.

Wheeler, Bob, Marco Torchiano, and Maintainer Marco Torchiano (2016). "Package 'ImPerm"'. In: $R$ package version, pp. 1.1-2.

Wohlfart, Christian et al. (2018). "TerraSAR-X and Wetlands: A Review". In: Remote Sensing 10.6, p. 916.

Yamaguchi, Yoshio et al. (2005). "Four-Component Scattering Model for Polarimetric SAR Image Decomposition". In: IEEE Transactions on Geoscience and Remote Sensing 43.8, pp. 1699-1706. 